\title{
Bacterial Etiology of Respiratory Tract Infections among Ambulatory School Children in Moshi Municipality, Tanzania
}

\author{
James Samwel Ngocho ${ }^{1,2,{ }^{*}, \text { Caroline Amour }}{ }^{3}$, Margaretha Sariko ${ }^{4}$, Blandina Theophil Mmbaga ${ }^{2,5}$, \\ Gibson Sammy Kibiki ${ }^{1,6}$
}

${ }^{1}$ Kilimanjaro Clinical Research Institute, Kilimanjaro Christian Medical University College, Moshi, Tanzania

${ }^{2}$ Kilimanjaro Christian Medical Centre, Duke University Collaboration Clinical Research Site, Moshi, Tanzania

${ }^{3}$ Haydom Global Health Institute, Manyara, Tanzania

${ }^{4}$ Clnical laboratory department, Kilimanjaro Christian Medical Centre, Moshi, Tanzania

${ }^{5}$ Department of pediatrics and child health, Kilimanjaro Christian Medical Centre, Moshi, Tanzania

${ }^{6}$ Department of Internal Medicine, Kilimanjaro Christian Medical Centre, Moshi, Tanzania

Email address:

jamesngocho08@gmail.com (J. S. Ngocho), lyneamour@gmail.com (C. Amour),m.sariko@kcri.ac.tz (M. Sariko), blaymt@yahoo.com (B. T. Mmbaga),g.kibiki@kcri.ac.tz (G. S. Kibiki)

\section{To cite this article:}

James Samwel Ngocho, Caroline Amour, Margaretha Sariko, Blandina Theophil Mmbaga, Gibson Sammy Kibiki. Bacterial Etiology of Respiratory Tract Infections among Ambulatory School Children in Moshi Municipality, Tanzania. Science Journal of Public Health. Vol. 3, No. 5, 2015, pp. 625-632. doi: 10.11648/j.sjph.20150305.15

\begin{abstract}
Background: Respiratory tract infections are the leading cause of morbidity and mortality in children worldwide. Management of respiratory tract infections poses a challenge in developing countries particularly due to limited resources for bacterial identification. The objective of this study was to describe bacterial etiological agents causing respiratory tract infections and their resistance patterns among ambulatory school children in Moshi municipality, Tanzania. Methodology: A cross sectional community based study was conducted, from January to March 2014 in 4 primary schools in Moshi Municipality. All school children available at the time of study were assessed for respiratory symptoms, those with selfreported respiratory tract symptoms for four days or more were eligible for participation. While those on medication and those who completed oral medication within 15 days prior to screening were excluded. Nasopharyngeal and throat swabs were collected from eligible children. Isolates were tested for sensitivity against commonly used antibiotics. Results: Of 2,016 screened school children, 474 (23.5\%) had respiratory tract symptoms. Respiratory tract bacterial pathogens were isolated from $123(73.7 \%)$ of 167 children whose nasopharyngeal and throat swabs were collected, three children did no show for swab collection. S. aureus was the most prevalent isolate 68 (55.3\%) followed by S. pneumoniae 43 (35.0\%), and the least prevalent isolate was K. pneumoniae 7 (5.7\%). Majority of isolated upper respiratory tract bacteria were resistant to ampicillin. $S$. pneumoniae exhibited the highest rate of the resistance whereby, 33 (91.7\%) isolates were resistant to ampicillin. However, the resistance of isolates to cotrimoxazole was found to be low. Gentamicin and ceftriaxone were effective against most isolates. Conclusion: Prevalence of respiratory tract symptoms was high among ambulatory school children who were presumed to be healthy. The observed high resistance of isolates might be due to unnecessary prescription of antibiotics, and counterfeit drugs. There is a need to strengthen school health program, in order to identify children with respiratory tract infections and refer them to a health facility for further evaluation.
\end{abstract}

Keywords: Respiratory Tract Infections, Bacterial Pathogens, Resistant Pattern

\section{Background}

Respiratory tract infections (RTI) are infections that affect the air passages, including the nasal passages, the bronchi and the lungs [1]. RTIs are classified into upper respiratory tract infection and lower respiratory tract 
infection. Most upper respiratory tract infections are caused by virus $(90.0 \%)$ followed by bacterial infections while coinfection occurs in $35-41 \%$ of cases [2,3]. Although viral RTIs are the commonest, bacterial RTIs are associated with severe morbidity, and high rates of mortality. The most frequent isolated bacterial pathogens causing respiratory tract infection in children are; $S$. pneumoniae, $S$. aureus, $K$. pneumoniae, S. pyogenes, $H$. influenzae and M. pneumoniae $[2,3,4,5,6]$.

RTIs are the most frequently reported infections in all age groups with acute respiratory tract infection (ARTI) being the leading cause of morbidity and mortality worldwide in children [7]. Worldwide about 30 to $50 \%$ of paediatric medical consultations are due to RTIs, resulting into 20 to $40 \%$ of hospitalization and $50 \%$ of them die of pneumonia [8]. It is estimated that in 2010, 1.4 million children died from RTIs with 11.9 million episodes of severe and 3.0 million episodes of very severe ARTIs [9]. According to $\mathrm{WHO}$, pneumonia alone kills 1.1 million children each year accounting for $18 \%$ of all deaths of children worldwide [1], and $50 \%$ of these deaths take place in Sub-Saharan Africa (SSA). Tanzania is among 15 countries with highest incidence of ARTIs in the world, with an estimated 1.9 million cases each year in under five [4].

RTIs can lead to a number of complications if left unattended, $12 \%$ children with ARTIs tend to develop complications [10]. Some of the known complications are; retropharyngeal abscess, empyema, bronchiectasis, meningitis, brain abscess, post-streptococcal glomerulonephritis and acute rheumatic fever [11,12].

Children with RTIs respond very well to antibiotics treatment but only $30 \%$ of children receive appropriate antibiotic [1]. There is wide spread miss use/over-use of antibiotics treatment especially for children in developing countries which may lead to just another challenge of drug resistance [13]. For instance, between September 2010 and March 2011, 80.0\% of children with cough in Moshi were prescribed antibiotic inappropriately [14]. Furthermore, researchers from Tanzania found that; antibacterial were available in unauthorized drug outlets, and were dispensed without a prescription [15]. Reports from different countries including those neighboring Tanzania, have reported resistance against recommended antibiotics for respiratory tract bacterial pathogens. For instance resistance to cotrimoxazole ranged from 9.1 to $83.5 \%[16,17]$ while that of penicillin at 3.3 to $93.3 \%[5,18]$.

In Tanzania and most developing countries, there is limited publication on the burden of RTIs among primary school children. Management of RTIs pose a challenge due to limited resources for the identification of the etiological agent and therefore administration of antibiotic is not guided by bacteriological sensitivity to the antibacterial agents, which increases risk of antibiotic resistance. This study aimed at providing evidence on the burden of RTIs among primary school children, identifying the common bacterial isolates and sensitivity pattern of isolated pathogens, thus to raise awareness and guide the empirical management of respiratory tract infections in children who are at school and presumed to be healthy.

\section{Methods}

\subsection{Study Population}

Moshi municipality has a total of 35 government primary schools, of them 4 were selected randomly for participation. At the time of screening, the total number of pupils in the selected four primary schools in Moshi municipality was 2,016. After written consent from respective school head teacher, all children from the selected school were screened for respiratory symptoms (cough, chest pain, chest tightness, wheezing, running nose, sneezing, and painful swallowing/sore throat). Study physician screed school children by inquiring the presence or absence of any respiratory symptom and the duration of the symptom (symptom for four days or more), and 268 children were eligible to participate in the study. Among them 170 (63.4\%) children were randomly selected for bacteriological study for which nasopharyngeal and throat swabs were collected for laboratory analysis. In each class, children with respiratory symptoms were identified, if the number of those meeting inclusion criteria was 6 or less all were invited for participation while in classes were the number of eligible children was more than 6 , randomly 6 were selected for participation. Among them, three pupils did not show up for swab collection; therefore, isolates were done from 167 pupils with self-reported respiratory symptoms. Children on antibiotic medication and those who completed antibiotic medication within 15 days prior to screening were excluded from the study.

\subsection{Collection of Nasopharyngeal and Throat Swabs}

Sterile polyester tipped applicator swab (Puritan medical products company llc Guilford, Maine USA) was carefully inserted into either of child nostril, and gently rubbed against the turbinate by rotating the swab. The swab was inserted into Stuart's transport medium bottle, then shaft of swab was broken off, and tube recapped. Children were then asked to open their mouth and a spatula was used to press the tongue downward to the floor of the mouth. Sterile polyester tipped applicator was used to swab both of the tonsillar arches and the posterior nasopharynx, then the shaft of swab was broken off and tube recapped. Specimens were transported at room temperature to the Kilimanjaro Christian Medical Centre (KCMC) clinical laboratory within 4 hours from the time of collection for processing.

\subsection{Laboratory Procedure}

Nasopharyngeal and throat specimens were processed at KCMC Clinical laboratory microbiology department according to Standard Operating Procedures (SOP). A swab of each specimen was taken from Stuart's transport medium and inoculated on Blood agar (BA), Chocolate (CA) and 
MacConkey agar (MCA) plates. Nasopharyngeal and throat swab from each participant was plated differently. The plates were incubated under micro-aerobic conditions in 5$10 \% \mathrm{CO}_{2}$ atmosphere (with exception of $\mathrm{MCA}$ ) at $35-37^{\circ} \mathrm{C}$ for 24-48 hours. Bacteria identification was performed based on culture morphology, culture characteristics, and Gram stain of the growing colonies on the plates followed by biochemical tests for species identification. For gram positive organisms; catalase test, coagulase test and hemolysis were used for species identification. While for gram negative; Triple Sugar Iron Agar (TSI), Indole test, Citrate utilization, Urease test and Kovac's oxidase test were used for species identification

Drug Susceptibility Test (DST) was performed using the Kirby-Bauer disc diffusion method according to Clinical and Laboratory Standards Institute guidelines (CLSI, 2010). A standardized inoculum of a bacterial isolate was swabbed onto the surface of a Mueller- Hinton agar plate. Filter paper disks impregnated with a standard amount of antimicrobial agents was placed on the agar, and then incubated overnight. The diameter of the zone of inhibition was measured around each disk. The zone sizes were compared to tables in the disc-diffusion tests and MICdetermination from the European Committee on Antimicrobial Susceptibility Testing (EUCAST 2010), to establish a qualitative report of susceptible, intermediate or resistant to each of the antimicrobial agents tested. The susceptibility of isolates were tested against the following drugs; ampicillin $(10 \mu \mathrm{g})$; chloramphenicol $(30 \mu \mathrm{g})$; gentamicin $(10 \mu \mathrm{g})$; ceftriaxone $(30 \mu \mathrm{g})$; cotrimoxazole $(1.25 / 23.75 \mu \mathrm{g})$.

\subsection{Statistical Analysis}

Data were double entered into EpiData 3.1 then exported to STATA/IC version 12.0 statistical software (StataCorp, U.S.A), for analysis. Chi square test and Fisher's exact test (when the expected frequency was less than 5) was used to investigate the association of the variables. All tests were two sided with $\mathrm{P}$ values $\leq 0.05$ regarded as statistically significant.

\section{Ethical Consideration}

KCMC Research Ethical Committee approved the study and Permission from both Moshi Municipal Director and Moshi Municipal primary schools education officer to conduct the study was granted. The aim of this study was explained at each ward health committee where the selected schools are located and verbal approvals were granted from these committees. Since the study included screening to all children in specific classes similar to other school program, ethics committee waived the need for parental consent and approved obtaining verbal assent from the school children, and head of school signed informed consent for their schools to participate in this study.

\section{Results}

In total 2,016 pupils were screened, among them, 474 $(23.5 \%)$ had respiratory tract symptoms. The female to male ratio were almost equal, female (51.8\%). Majority presented with cough $(80.0 \%)$, running nose $(61.2 \%)$, chest pain $(57.7 \%)$ and sneezing $(56.5 \%)$. The mean age $( \pm S D)$ of participants at enrollment was $10( \pm 2.1)$ years. Most of study participants were from school B (31.2\%) followed by school D (26.5\%). Regarding the class of study, more participants were from class five $(16.5 \%)$. Table 1 below shows the general characteristics of study participants.

Table 1. General characteristics of study participants $(N=170)$.

\begin{tabular}{|c|c|c|}
\hline Variables & $\mathbf{N}$ & $\%$ \\
\hline \multicolumn{3}{|l|}{$\operatorname{Sex}$} \\
\hline Male & 82 & 48.2 \\
\hline Female & 88 & 51.8 \\
\hline \multicolumn{3}{|c|}{ Age categories, years } \\
\hline $6-9$ & 66 & 38.8 \\
\hline $10-12$ & 80 & 47.1 \\
\hline $13-15$ & 24 & 14.1 \\
\hline \multicolumn{3}{|c|}{ Mean age $( \pm$ SD) $10( \pm 2.1)$} \\
\hline \multicolumn{3}{|l|}{ School } \\
\hline A & 30 & 17.6 \\
\hline $\mathrm{B}$ & 53 & 31.2 \\
\hline $\mathrm{C}$ & 42 & 24.7 \\
\hline $\mathrm{D}$ & 45 & 26.5 \\
\hline \multicolumn{3}{|c|}{ Education, class } \\
\hline One & 21 & 12.4 \\
\hline Two & 23 & 13.5 \\
\hline Three & 24 & 14.1 \\
\hline Four & 23 & 13.5 \\
\hline Five & 28 & 16.5 \\
\hline Six & 25 & 14.7 \\
\hline Seven & 26 & 15.3 \\
\hline
\end{tabular}

Among children with respiratory tract infection, nasopharyngeal and throat swab were collected in 167 pupils who met inclusion criteria. Of the 167 pupils whose nasopharyngeal and throat swabs were tested for bacterial isolates and antibiotic sensitivity, $123(73.7 \%)$ had one or more bacteria isolates with $S$. aureus 68 (55.3\%) and $S$. pneumoniae $43(35.0 \%)$ being the most prevalent upper respiratory tract isolates with $K$. pneumoniae 7 (5.7\%) being the least isolate. Figure 1 below shows the prevalence of isolated upper respiratory tract bacterial pathogens. 


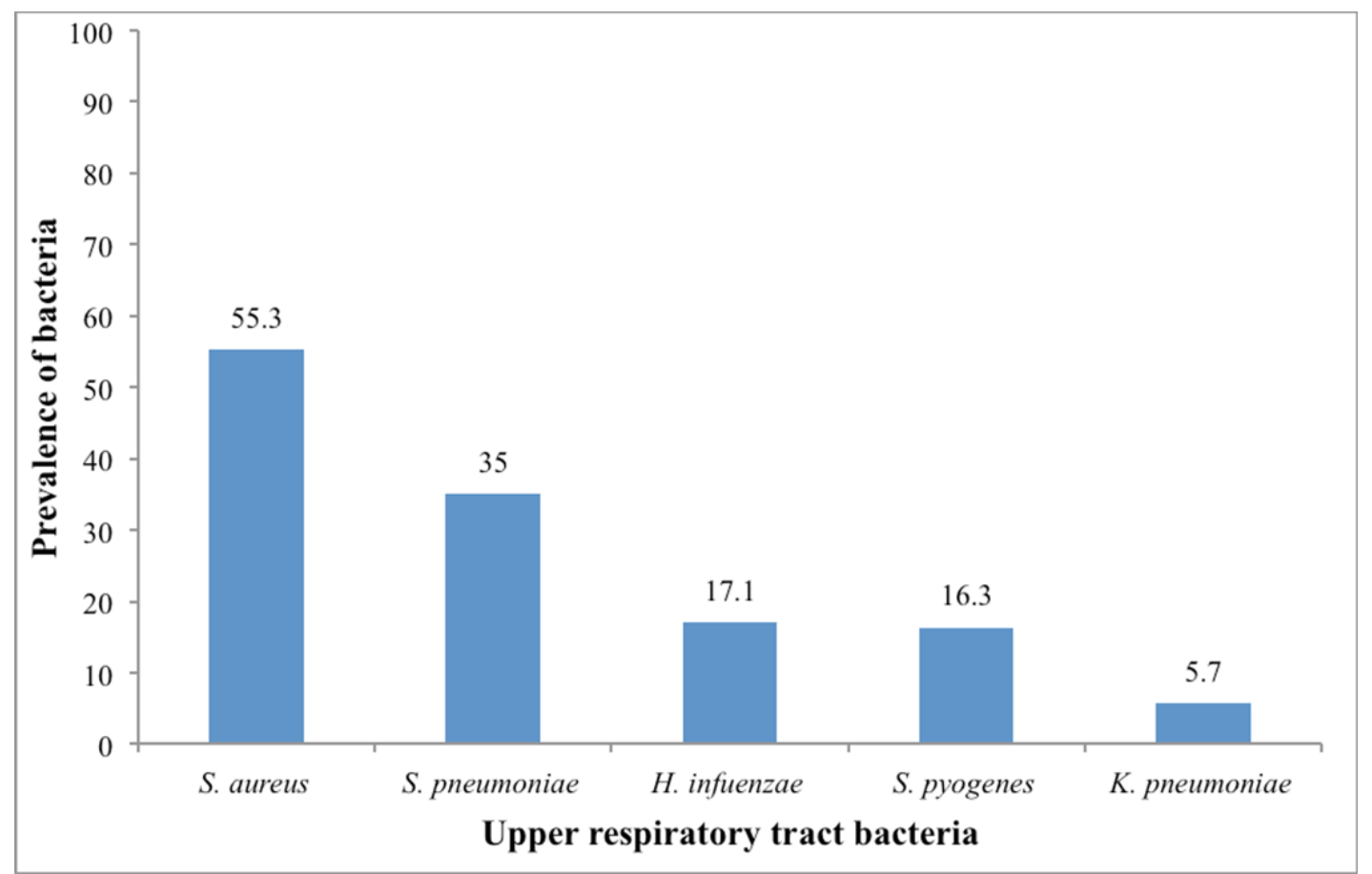

Figure 1. Prevalence of upper respiratory tract bacterial isolates from school children with respiratory tract symptoms ( $n=123)$.

Most of isolates were from children aged 10-12 years, in which $30(44.1 \%)$ of $S$. aureus and $5(71.43 \%)$ of $K$. pneumoniae were isolated from this age group. In general, there was statistical significant difference in the prevalence of $S$. pyogenes and $S$. pneumoniae between age groups and isolated bacterial pathogens $(\mathrm{P}<0.05)$ as shown in Table 2 below.

Table 2. Age distribution of children with respiratory tract symptoms by bacterial pathogens $(n=123)$.

\begin{tabular}{lllll}
\hline \multirow{2}{*}{ Isolate } & \multicolumn{3}{l}{ Age categories in years n (\%) } & p- \\
\cline { 2 - 3 } & $\mathbf{6 - 9}$ & $\mathbf{1 0 - 1 2}$ & $\mathbf{1 3 - 1 5}$ & value* \\
\hline S. pneumoniae & & & & \\
Yes & $15(23.4)$ & $15(19.0)$ & $13(54.2)$ & 0.012 \\
No & $49(76.4)$ & $64(81.0)$ & $11(55.8)$ & \\
S. Aureus & & & & \\
Yes & $26(40.6)$ & $30(38.0)$ & $12(50.0)$ & 0.747 \\
No & $38(59.4)$ & $49(62.0)$ & $12(50.0)$ & \\
K. pneumoniae & & & & \\
Yes & $1(1.6)$ & $5(6.3)$ & $1(4.3)$ & 0.060 \\
No & $65(98.4)$ & $74(93.7)$ & $23(95.8)$ & \\
S. pyogenes & & & & \\
Yes & $11(17.2)$ & $9(11.4)$ & 0 & 0.028 \\
No & $53(82.8)$ & $70(88.6)$ & $24(100)$ & \\
H. influenzae & & & & \\
Yes & $8(12.5)$ & $10(14.5)$ & $3(12.5)$ & 1.000 \\
No & $54(87.5)$ & $69(85.5)$ & $21(87.5)$ & \\
\hline
\end{tabular}

*Chi squared $\mathrm{p}$ value for linear trend
Most of S. pneumoniae isolates were from pupils in school A, $18(41.9 \%)$ and most of $S$. pyogenes were from pupils in school B, $11(55.0 \%)$, while there was no $S$. pyogenes isolated from pupils in school A. Similarly, there was no $K$. pneumoniae isolated from pupils in school $\mathrm{D}$. There was no statistically significant difference in the prevalence of respiratory tract bacterial isolates from these schools (Fisher's exact $>0.05$ ). See Table 3 below.

Table 3. Distribution of respiratory tract bacterial isolates by schools $(n=123)$.

\begin{tabular}{|c|c|c|c|c|c|}
\hline \multicolumn{6}{|c|}{ Schools n (\%) } \\
\hline Isolates & $\mathbf{A}$ & B & $\mathbf{C}$ & D & Total \\
\hline $\begin{array}{l}S . \\
\text { pneumoniae }\end{array}$ & $18(41.9)$ & $7(16.3)$ & $8(18.6)$ & $10(23.2)$ & $43(100)$ \\
\hline S. aureus & $12(17.7)$ & $19(27.9)$ & $17(25.0)$ & $20(29.4)$ & $68(100)$ \\
\hline $\begin{array}{l}K . \\
\text { pneumoniae }\end{array}$ & $3(42.9)$ & $1(14.2)$ & $3(42.9)$ & $0(0.0)$ & $7(100)$ \\
\hline S. pyogenes & $0(0.0)$ & $11(55.0)$ & $5(25.0)$ & $4(20.0)$ & $20(100)$ \\
\hline $\begin{array}{l}H . \\
\text { influenzae }\end{array}$ & $6(28.6)$ & $3(14.3)$ & $7(33.3)$ & $5(23.8)$ & $21(100)$ \\
\hline Total & $39(24.5)$ & $41(25.8)$ & $40(25.2)$ & $39(24.5)$ & $\begin{array}{l}159 \\
(100)\end{array}$ \\
\hline
\end{tabular}

Of the isolated 159 bacteria, 134 isolated were subjected to antimicrobial susceptibility testing. Among the gram positive bacteria, resistance to ampicillin was high; 33 (91.7\%) for $S$. pneumoniae and 53 (84.1\%) for S. aureus. The resistant of $S$. pneumoniae and $S$. aureus to cotrimoxazole was $25 \%$ and $9.5 \%$, respectively. Gentamicin and ceftriaxone were the most effective antibiotics, whereby; almost all isolated $S$. pyogenes and $H$. influenzae were sensitive to gentamicin while all isolated $H$. influenzae were sensitive to ceftriaxone 
with only $1(2.8 \%)$ of $S$. pneumoniae being resistant to ceftriaxone. See Table 4 below.

Table 4. The antimicrobial resistance pattern of isolated bacteria from children with respiratory symptoms.

\begin{tabular}{|c|c|c|c|c|c|}
\hline \multirow{2}{*}{$\begin{array}{l}\text { Antimicrobial agent } \\
\text { (concentration) }\end{array}$} & \multicolumn{5}{|c|}{ Resistance pattern n (\%) } \\
\hline & $\begin{array}{l}\text { S. pneumoniae } \\
\mathrm{n}=36\end{array}$ & $\begin{array}{l}\text { S. Aureus } \\
\mathrm{n}=63\end{array}$ & $\begin{array}{l}\text { K. pneumoniae } \\
\mathrm{n}=7\end{array}$ & $\begin{array}{l}\text { S. pyogenes } \\
\mathrm{n}=17\end{array}$ & $\begin{array}{l}\text { H. influenzae } \\
\mathrm{n}=11\end{array}$ \\
\hline Ampicillin $(10 \mu \mathrm{g})$ & $33(91.7)$ & $53(84.1)$ & $6(85.7)$ & $15(88.2)$ & $7(63.6)$ \\
\hline Chloramphenicol $(30 \mu \mathrm{g})$ & $6(16.7)$ & $12(19.0)$ & $2(28.6)$ & $7(41.1)$ & $1(9.0)$ \\
\hline Gentamicin $(10 \mu \mathrm{g})$ & $4(11.1)$ & $6(9.5)$ & $1(14.3)$ & 0 & 0 \\
\hline Ceftriaxone $(30 \mu \mathrm{g})$ & $1(2.8)$ & $8(12.7)$ & $2(28.6)$ & $1(5.9)$ & 0 \\
\hline Cotrimoxazole $(10 \mu \mathrm{g})$ & $9(25.0)$ & $6(9.5)$ & $2(28.6)$ & $3(17.7)$ & $4(36.4)$ \\
\hline
\end{tabular}

\section{Discussion}

There was high prevalence of respiratory tract infections in school children who otherwise were regarded as healthy; for every four children there was one with respiratory tract symptoms. The risk of transmitting the respiratory pathogens is very high considering the overcrowding of children in the class. Children with respiratory tract infection may transmit the pathogens to other children; with a possibility of a new infected child to take pathogens back home risking vulnerable groups such as under-five, and old people [19]. Parents and the community at large disregard respiratory tract symptoms and a good number of these infections will go without treatment, putting $12 \%$ of these children at a risk of developing complications $[9,10]$. At school where these children spend more time, there are no well stipulated health programs or screening program to identify children with respiratory tract infections. In fact the schools are good strategic points which can help in the fight against these common but potentially serious infections, as far as complications are concerned.

Though there are sporadic studies in this age group, our results are similar with those from north-east Tanzania among 1-18 years children, where the prevalence of respiratory tract symptoms was $22 \%$ [20,21]. Similarly, a study from Kenya reported high prevalence of respiratory tract infections in school children [22]. However, a study from India reported a low prevalence of respiratory tract infections among school children [23]. The prevalence variation might have been attributed to the sampling frame, age category of study participants and seasonal variation during the different study period.

$S$. aureus was identified as the most frequent bacterial isolate from children with respiratory tract symptoms. Many studies in the past have identify $H$. influenzae and $S$. pneumoniae as the most prevalent respiratory tract bacterial pathogens causing respiratory tract infections, contrary to this study $[3,5]$. The shift in the bacterial etiological agent might have been due to the inclusion of school-aged children; whereas, most of the previous studies were from under-five children. Secondly, the introduction of pneumococcal vaccine and $H$. influenzae type $\mathrm{b}$ vaccine in the national program of immunization might have contributed to the low prevalence of these respiratory tract bacterial pathogens compared to $S$. aureus. With the evidence from Gambian study, where introduction of Hib vaccine was associated with a decline in Hib carriage among young children from $12 \%$ to $0.25 \%$ [24]. This might have played role in low transmission rate of $H$. influenzae and hence, low prevalence in school aged children. Similarly, studies from Italy, Netherlands and Lithuania have reported a high prevalence of $S$. aureus ranging from $35.0 \%$ to $67.3 \%$ [25-28]. However a study from Nigeria reported a low prevalence $(5.4 \%)$ of $S$. aureus among children with respiratory tract symptoms [5]. It does appear that the prevalence of $S$. aureus in healthy children and children with symptoms varies widely by geography, age and season.

The second most common isolate was $S$. pneumoniae (35.0\%); several authors have reported similar findings from different parts of the world. In most of these studies $S$. pneumoniae was identified as leading cause of respiratory tract infections in children less than 5 year with a shift in school children. A study from Kenya, reported a similar prevalence $35.7 \%$ of $S$. pneumoniae [29]. Lower prevalence have been reported with researcher from Turkey and Nigeria, they found the prevalence of $23.4 \%$ and $6.8 \%$, respectively [17]. However, our prevalence of $S$. pneumoniae does appear to be lower compared with those from India, Gambia and Australia which reported prevalence at 53.4\%, 85.1\% and $67.0 \%$, respectively $[18,20,25]$.

The study has shown a high prevalence of $S$. pyogenes in this age group, with many children presenting with sore throat. When streptococcal pharyngitis infections are left unattended within 9 days from the onset of symptoms, the chances of developing complications or healing with sequel is very high. Some strains of Group A streptococcal are rheumatogenic causing acute rheumatic fever and $60.0 \%$ of acute renal injury (ARF) cases end up with rheumatic heart disease. Given the fact that the average duration of symptoms was above 9 days and it is estimated that $3-5 \%$ of population has an inherent susceptibility to ARF. A number of children in Tanzania suffering from sore throat are at a risk of developing ARF and some of them will complicate into rheumatic heart disease (RHD). The risk of developing ARF increases with recurrent sore throat infections. Our projecting is supported with 2008-2009 cardiac surgery experience at Muhimbili National Hospital; data have shown that $47.0 \%$ of performed cardiac surgeries were due to RHD [30]. Reports from developed countries have shown a decline in the 
incidence of RHD which might not be the case in developing countries, given the overcrowding in home and in classes, living conditions, poverty and poor accessibility to health care in these countries. With our findings, a number of children are at a risk of developing renal conditions later in their lives, since the risk of developing renal conditions in later life is three times higher with childhood post streptococcal glomerulonephritis and the risk increases with repeated episodes [31]. Studies from Nepal and Nigeria, have reported a similar high prevalence $S$. pyogenes in this age group [5,32].

In general most respiratory tract bacterial isolates were sensitive to ceftriaxone and gentamicin, with a very high resistance to ampicillin. The resistance to recommended and commonly used antibiotics for treatment of respiratory tract infections was high. This might be due to the fact that these drugs are readily available from drug outlets, cheap and easily accessible even without a prescription; with expected misuse. In most cases respiratory tract infections are treated empirically which just adds another risk for resistance development [15]. The risk of transmitting these resistant strains of respiratory tract bacteria is very high in the community since the community disregards respiratory tract infections. There is a lot of unnecessary prescription of antibiotics especially for acute viral respiratory tract infection, and the issues of counterfeit drugs, long shelf life and expired antibiotics are adding to this problem of resistance. Study results conform to studies from Uganda, Italy, Turkey and Nigeria which reported high resistance $S$. pneumoniae, $S$. aureus, $K$. pneumoniae and $S$. pyogenes against penicillin and its derivatives $[5,16,17,25]$. However, few studies from different countries have shown different results. Finding from Central Africa Republic, India and Gambia reported the resistance of $S$. pneumoniae against penicillin and its derivatives at $8.8 \%, 3.3 \%$ and $14.3 \% \quad(18,24,33]$. The seen variation in resistance of respiratory tract isolates against penicillin/ampicillin may be due to the geographical distribution of resistant strains and country specific policy on the accessibility and use of recommended antibiotics for respiratory tract infections and other bacterial infections.

\section{Conclusion}

In this study we found a high prevalence of respiratory symptoms among ambulatory school children who were presumed to be healthy, which raises the need for addressing the situation. This may be due to the overcrowding of children in the class, and the fact that these symptoms are disregarded by the parents. The observed high resistance of isolates might be due to increase in empirically treatment of respiratory tract infections with unnecessary prescription of antibiotics, and counterfeit drugs. There is a need to strengthen the available school health program, to be able to identify pupils with respiratory tract infections, and refer them to a health facility for further evaluations. The use of cotrimoxazole in the treatment of uncomplicated respiratory tract infections should be considered.

\section{Strength and Limitations}

One of the limitations of our study was the use of conversional culture method which has low sensitivity in detecting bacterial pathogen (swabs from 44 children with respiratory symptoms had no bacteria growth) and that the media used were not able to culture some of the known bacterial pathogens at this age group. But still we were able to demonstrate the burden of respiratory tract infections in the community where children are presumed to be healthy. This is one of the few community studies in Moshi municipality done among school children and the study has involved both clinical and bacteriology assessment which add to its strength.

\section{Authors' contributions}

JSN conceived the study, design, coordinated data collection, and led analysis, interpretation and manuscript preparation. CA participated in data collection, analysis and manuscript preparation. MS coordinated sample processing and participated in manuscript preparation.

BTM participated in interpretation of the findings and manuscript writing.

GSK participated in study design, interpretation of the findings, manuscript preparation and final review of manuscript.

\section{Author's Information}

James Samwel Ngocho, MD, MSc. Clinical Research, Study coordinator in HIV/AIDS clinical trial studies at KCMC-Duke University Collaboration

Caroline Amour BSc. Molecular biology and applied biotechnology, MSc. Epidemiology and Applied Biostatistics

Margret Sariko BSc. Laboratory, MSc. Clinical Research, $\mathrm{PhD}$ candidate

Blandina Theophil Mmbaga MD, Mmed, PhD, Pediatrician and KCMC-Duke University Collaboration site leader, senior lecturer at the KCMUCo.

Gibson Sammy Kibiki, MD, Mmed, PhD, Professor of Medicine KCMUCo. and Director Kilimanjaro Clinical Research Institute

\section{Acknowledgements}

This study was EDTCP funded through East African Consortium for Clinical Research. The funding agency had no role in study design, data collection, analysis/interpretation or manuscript preparation, and in the decision to submit manuscript for publication. We thank all participants, and school administration. We would also like to thank Kilimanjaro Christian Medical Centre for their support in sample processing. Finally, Kilimanjaro Christian Medical University College for organizing masters of Science in clinical research. 


\section{References}

[1] WHO. Fact sheet N`331 Reviewed November 2013. 2013;(November).

[2] Mcintosh K. Community - Acquired pneumonia in children. N Engl J Med. 2002;346(6):429-37.

[3] Tsolia MN, Psarras S, Bossios a, Audi H, Paldanius M, Gourgiotis D, et al. Etiology of community-acquired pneumonia in hospitalized school-age children: evidence for high prevalence of viral infections. Clin Infect Dis. 2004 Sep 1;39(5):681-6.

[4] Rudan I, Boschi-Pinto C, Biloglav Z, Mulholland K, Campbell H. Epidemiology and etiology of childhood pneumonia. Bulletin of the World Health Organization. 2008. p. $408-16$.

[5] Ei N, Ezute S, Cc EN, Cc O, Eze C. Bacteria etiological agents causing respiratory tract infections in children and their resistance patterns to a panel of ten antibiotics. Asian Pacific J Trop Dis. 2012;18-23.

[6] Boloursaz MR, Lotfian F, Aghahosseini F, Cheraghvandi A, Khalilzadeh S, Farjah A, et al. Epidemiology of Lower Respiratory Tract Infections in Children. J Compr Pediatr. 2013 Mar 2;3(3):93-8.

[7] Bellos A, Mulholland K, Brien KLO, Qazi SA, Gayer M, Checchi F. The burden of acute respiratory infections in crisisaffected populations: a systematic review. Confl Health. $2010 ; 1-12$.

[8] Cashat-Cruz M, Morales-Aguirre JJ, Mendoza-Azpiri M. Respiratory tract infections in children in developing countries. Semin Pediatr Infect Dis. 2005 May;16(2):84-92.

[9] Nair H, Simões E a F, Rudan I, Gessner BD, AzzizBaumgartner E, Zhang JSF, et al. Global and regional burden of hospital admissions for severe acute lower respiratory infections in young children in 2010: a systematic analysis. Lancet. 2013 Apr 20;381(9875):1380-90.

[10] Hayward G, Thompson M, Hay AD. What factors influence prognosis in children with acute cough and respiratory tract infection in primary care? BMJ. 2012 Jan;345(September):e6212.

[11] Denny FW. Acute Respiratory Infections in Children: Etiology and Epidemiology. Pediatrics in Review. 1987. p. 135-46.

[12] Carepetis J, Brown A, Maguire G, Walsh W, Noonan S, Thompson D. The Australian guideline for prevention, diagnosis and management of acute rheumatic fever and rheumatic heart disease ( 2nd edition ). Menzies; 2012.

[13] Keith T, Saxena S, Murray J, Sharland M. Risk-benefit analysis of restricting antimicrobial prescribing in children: what do we really know? Curr Opin Infect Dis. 2010 Jun;23(3):242-8.

[14] Gwimile JJ, Shekalaghe SA, Kapanda GN, Kisanga ER. Antibiotic prescribing practice in management of cough and/or diarrhoea in Moshi Municipality, Northern Tanzania: cross-sectional descriptive study. Pan Afr Med J. 2012 Jan;12:103.
[15] Boogaard JVANDEN, Semvua HH, Boeree MJ, Aarnoutse RE Assessment of antibacterial sale by using the Anatomic Therapeutic Chemical classification and Defined Daily Dose methodology in Moshi Municipality, northern Tanzania. Tanzan J Health Res. 2010;12(3).

[16] Joloba ML, Bajaksouzian S, Palavecino E, Whalen C, Jacobs MR. High prevalence of carriage of antibiotic-resistant Streptococcus pneumoniae in children in Kampala Uganda. Int J Antimicrob Agents. 2001;17:395-400.

[17] Gazi H, Kurutepe S, Sürücüoğlu S, Teker A, Ozbakkaloglŭ B. Antimicrobial susceptibility of bacterial pathogens in the oropharynx of healthy school children in Turkey. Indian J Med Res. 2004 Nov;120(5):489-94.

[18] Jain A, Kumar P, Awasthi S. High nasopharyngeal carriage of drug resistant Streptococcus pneumoniae and Haemophilus influenzae in North Indian schoolchildren. Trop Med Int Health. 2005 Mar;10(3):234-9.

[19] Telmesani AM a, Ghazi HO. A study of group a streptococcal bacteria isolation from children less than 12 years with acute tonsillitis, pharyngitis and healthy primary school children. $\mathrm{J}$ Family Community Med. 2002 May;9(2):23-6.

[20] Chandler CIR, Nadjm B, Boniface G, Juma K, Reyburn H, Whitty CJM. Assessment of Children for Acute Respiratory Infections in Hospital Outpatients in Tanzania: What Drives Good Practice? Am J Trop Med Hyg. 2008;79(6):925-32.

[21] Reyburn H, Mwakasungula E, Chonya S, Mtei F, Bygbjerg I, Poulsen A, et al. Clinical assessment and treatment in paediatric wards in the north-east of the United Republic of Tanzania. Bull World Health Organ. 2008 Feb 1;86(2):123-39.

[22] Berkley J a, Maitland K, Mwangi I, Ngetsa C, Mwarumba S, Lowe BS, et al. Use of clinical syndromes to target antibiotic prescribing in seriously ill children in malaria endemic area: observational study. BMJ. 2005 Apr 30;330(7498):995.

[23] Goel K, Ahmad S, Agarwal G, Goel P, Kumar V. A Cross Sectional Study on Prevalence of Acute Respiratory Infections (ARI) in Under-Five Children of Meerut District, India. J Community Med Health Educ. 2012;02(09):2-5.

[24] Hill PC, Akisanya A, Sankareh K, Cheung YB, Saaka M, Lahai G, et al. Nasopharyngeal carriage of Streptococcus pneumoniae in Gambian villagers. Clin Infect Dis. 2006 Sep 15;43(6):673-9.

[25] Zanelli G, Sansoni A, Zanchi A, Cresti S, Pollini S. Staphylococcus aureus nasal carriage in the community: a survey from central Italy. Epidemiol Infect. 2002;417-20.

[26] Bogaert D, Van Belkum A, Sluijter M, Luijendijk A, De Groot $\mathrm{R}$, Rümke $\mathrm{HC}$, et al. Colonisation by Streptococcus pneumoniae and Staphylococcus aureus in healthy children. Lancet. 2004;363(9424):1871-2.

[27] Pavilonyte Z, Kacerauskiene J, Budryte B, Keizeris T, Junevicius J, Pavilonis A. [Staphylococcus aureus prevalence among preschool- and school-aged pupils]. Medicina (Kaunas). 2007 Jan;43(11):887-94.

[28] Pavilonyt Ž, Kauk R, Antu A, Pavilonis A. KLINIKINIAI TYRIMAI Staphylococcus aureus paplitimas hospitalizavimo laikotarpiu. Medicina (B Aires). 2008;44(8). 
[29] Abdullahi O, Nyiro J, Lewa P, Slack M, Scott JAG. The descriptive epidemiology of Streptococcus pneumoniae and Haemophilus influenzae nasopharyngeal carriage in children and adults in Kilifi district, Kenya. Pediatr Infect Dis J. 2008 Jan 15;27(1):59-64.

[30] Nyawawa E, EV U, Chillo P, Waane T, Lugazia E, Mpoki U, et al. Cardiac Surgery: One Year Experience of Cardiac Surgery at Muhimbili National Hospital, Dar es Salaam , Tanzania. East Cent African J Surg. 2010;15(1):111-8.

[31] White A V, Hoy WE, Mccredie DA. Childhood post streptococcal glomerulonephritis as a risk factor for chronic renal disease in later life chronic renal disease in later life. MJA. 2001;174(10):492-6.

[32] Dumre S, Sapkota K, Adhikari N, Achary D, Karki M, Bista S, et al. Asymptomatic throat carriage rate and antimicrobial resistance pattern of. Kathmandu Univ Med J. 2009;7 No. 4(28):392-6.

[33] Ndoyo J, Siopathis RM, Klugman KP, Wasas A. Antibiotic resistance among nasopharyngeal isolates of Streptococcus pneumoniae and Haemophilus influenzae--Bangui, Central African Republic, 1995. MMWR Morb Mortal Wkly Rep. 1997;46(3):62-4. 